\title{
Development of a paper-based microfluidic device for the quantification of ammonia in industrial wastewater
}

\author{
Nonhlazeko Loveday Nxumalo', Lawrence Mzukisi Madikizela', Hendrik Gert Kruger², Stanley Chibuzor Onwubu \\ and Phumlane Selby Mdluli ${ }^{1}$ \\ 'Department of Chemistry, Durban University of Technology, PO Box 1334, Durban, 4001, South Africa \\ ${ }^{2}$ Catalysis and Peptide Research Unit, School of Health Sciences, Westville campus, University of KwaZulu-Natal, Durban, 4000, South Africa \\ ${ }^{3}$ Dental Sciences, Durban University of Technology, PO Box 1334, Durban, 4001, South Africa
}

Ammonia is a toxic pollutant increasingly found in urban and industrial wastewater and unprotected surface water. Industry discharges and fertilizer run-off release ammonia into sewers and streams, overloading wastewater treatment plants and causing fish deaths in surface water such as rivers, sea and lakes. The purpose of this study was to develop and evaluate the effectiveness of the microfluidic paper-based device ( $\mu$ PAD) for the quantification of ammonia in wastewater. The $\mu P A D$ fabricated had an oval-shaped pattern which was designed using CorelDraw software. The hydrophilic zones were created by printing a chromatographic paper with a Xerox wax printer (Xerox colorqube 8570). The modified version of the colorimetric method using Nessler reagent was combined with microfluidic technologies to create a low-cost monitoring system for detection of ammonia in wastewater. The method allows for ammonia determination in the range of $0-5$ $\mathrm{ppm}(\mathrm{mg} / \mathrm{L})$ with a limit of detection of $3.34 \mathrm{ppm}$. This study indicated that a $\mu$ PAD was successfully used to quantify the concentration of ammonia in wastewater.

\section{INTRODUCTION}

Ammonia $\left(\mathrm{NH}_{3}\right)$ is a chemical with widespread application/production in different industries. It is the most commonly occurring nitrogenous pollutant in wastewater (Lee et al., 2009). Ammonia can be present as either gaseous $\mathrm{NH}_{3}$ or ammonium ion $\left(\mathrm{NH}_{4}^{+}\right)$in aqueous solutions, depending on solution $\mathrm{pH}$. The presence of ammonia in wastewater is regarded as a major concern due to its toxicity. Toxicity of ammonia can be problematic to fish and other aquatic animals, resulting in the depletion of dissolved oxygen (Colt and Huguenin, 2002) as well as eutrophication (Jorgensen, 2002). It is already reported that a concentration as low as $0.2 \mathrm{ppm}(\mathrm{mg} / \mathrm{L})$ can be fatal to aquatic organisms (Wiesmann, 1994).

The guideline levels for ammonia concentrations released into receiving water bodies vary in different parts of the world. The United States Environmental Protection Agency (USEPA) and the American Committee on Water Quality Criteria recommend a value of below $0.02 \mathrm{ppm}(\mathrm{mg} / \mathrm{L})$ nitrogen-ammonia (Jorgensen, 2002). Therefore, regulatory agencies require industries to treat ammonia in their effluents to meet these stringent requirements. However, some existing wastewater treatment plants (WWTP) are unable to comply with these regulations as their service load increases. Industries are also experiencing increased regulations on their wastewater and are being cut-off from sewer discharge.

Currently, monitoring ammonia in wastewater is primarily based on manual sampling followed by analysis using standard laboratory methods. This results in the infrequent monitoring of wastewater at a much lower number of locations than is desirable, as it is time-consuming, expensive, non-scalable and requires skilled personnel. Therefore, it is of great importance to seek an efficient, practical, timeas well as cost-effective, and sensitive method for the detection of ammonia in wastewater.

Numerous methods for the identification and quantification of ammonia such as potentiometric (Jayawardane et al., 2015), colorimetric (Amirjani and Fatmehsari, 2018) and titrimetric (Thompson and Morrison, 1951) measurements have been reported in literature. However, these analytical methods each have their own restrictions, and different levels of investment in equipment, operating costs, secondary pollution, and other deficiencies (Guo et al., 2008; Islam and Patel, 2010; Luo et al., 2015; Markou et al., 2014; Yang and Cheng, 2007).

Consequently, there has been great interest in developing a portable, sensitive and optical ammonia sensor which is operable at ambient conditions and capable of detecting ammonia at parts-permillion levels (Srivastava et al., 2012). It has been suggested that a low-cost microfluidic paperbased analytical device offers an opportunity to tackle this need, thereby increasing the frequency and geographic coverage of environmental monitoring while also reducing analytical costs and complexity of measurement (Meredith et al., 2016).

Microfluidic paper-based analytical devices ( $\mu$ PADs) have been developed using various patterning technologies to reproducibly create low-cost lab-on-chip types of analytical tools (Yamada et al., 2015). Consequently, these devices are useful for field-deployable measurements in the areas of healthcare
CORRESPONDENCE

Phumlane Selby Mdluli

\section{EMAIL}

phumlaneM@dut.ac.za

\section{DATES}

Received: 8 April 2019

Accepted: 2 June 2020

\section{KEYWORDS}

ammonia microfluidic device quantification

\section{COPYRIGHT}

(c) The Author(s)

Published under a Creative Commons Attribution 4.0 International Licence (CC BY 4.0) 
diagnostics, environmental monitoring and forensic analysis. These devices are portable, cost-effective and easily reproducible (Gong and Sinton, 2017; Martinez et al., 2010). One of the significant characteristics of $\mu \mathrm{PADs}$ is that they are extremely flexible. Thus, they can be adjusted to any application, particularly in low-resource settings.

The most widely used analytical method performed with paper devices is the simple yet effective colourimetric assay. Colorimetric detection is a well-established, fundamental method that has been the most widely adopted sensing mechanism for microfluidics paper-based analytical devices (Nie et al., 2012). This paper describes the use of the developed microfluidic paperbased analytical device ( $\mu \mathrm{PAD})$ combined with colorimetric detection chemistries for the quantification and detection of ammonia in wastewater. In particular, the most commonly used spectrophotometric color reaction in ammonia monitoring is that of Nessler reagent $\left(\mathrm{K}_{2} \mathrm{HgI}_{4}\right)$. This method is the preferred method and has the advantages of easy operation and high sensitivity. The colorimetric detection of ammonia includes the use of a Nessler reagent and salicylate method. In the Nessler reagent method, mercury (II) chloride and potassium iodide react with ammonia to form a yellow-brown coloured compound (Koch and McMeekin, 1924).

The XYZ tristimulus values unfortunately have constrained use as colour descriptions since they correspond poorly with visual traits. While $\mathrm{Y}$ relates to value (lightness), $\mathrm{X}$ and $\mathrm{Z}$ do not correlate to hue and chroma. It is therefore not particularly perceptually uniform (Baldevbhai and Anand 2012). Thus, when the 1931 CIE (Fairchild, 1993) standard observer was established, the commission endorsed using the chromaticity coordinates $L^{*} a^{*} b^{*} /$ Yxy. Since the smartphone camera acquires images in the RGB colour space, the smartphone image information of RGB values was processed to obtain $L^{*}, a^{*}$ and $b^{*}$ values using an empirical colour space conversion model (Hunter Lab) (León et al., 2006; Wyszecki, 1968). The CIELAB colour space has a uniform colour distribution, and is very close to human perception of colour. The colour is represented by a point; this therefore allows high precision. More so, $L^{*} a^{*} b^{*}$ values do not elucidate absolute colours except if the white reference is also specified. Frequently, the white reference is assumed to follow a standard and is not directly specified (Consortium, 2004).

\section{Colorimetry}

The addition of Nessler reagent to the solution containing ammonia leads to a change in the appearance of the solution, i.e., the colourless initial solution converts to intense yellow. The formation of $\mathrm{NH}_{2} \mathrm{Hg}_{2} \mathrm{I}_{3}$ compound is responsible for this colour change which provides real-time and observable monitoring of the system. It was then possible to automatically capture images of the observed colour. After capturing, the required images were measured using computer software, i.e., Adobe photoshop and ImageJ. The mean gray value (intensity) and the RGB (red, green, blue) values were extracted using ImageJ software.

\section{MATERIALS AND METHODS}

\section{Chemicals and apparatus}

Mercury (II) chloride (99\%), potassium sodium tartrate and sodium nitroferricyanide (99\%) were purchased from SigmaAldrich (Steinheim, Germany). Potassium iodide, sodium hydroxide (99\%), sodium salicylate and ammonium chloride were purchased from Merck (Darmstadt, Germany). A Cary 50 Conc UV-visible spectrophotometer purchased from SMM Instruments PTY (LTD) (Cape Town). A Samsung Galaxy J1 smartphone was purchased from Game (Durban, South Africa).

\section{Preparation of reagents}

\section{Nessler's reagent}

Nessler reagent was prepared by dissolving $4.4 \mathrm{~g}$ of mercury (II) chloride in $40 \mathrm{~mL}$ distilled water. Complete dissolution was achieved by heating the solution on the hot plate. In a separate flask, $11.0 \mathrm{~g}$ of potassium iodide was dissolved in the minimum possible amount of water (approximately $2 \mathrm{~mL}$ ). This saturated solution of potassium iodide (KI) was then added drop-wise into the prepared solution of mercury (II) chloride. This resulted in abundant precipitation of orange mercury (II) Iodide $\left(\mathrm{HgI}_{2}\right)$. A $100 \mathrm{~mL}$ solution of $5 \mathrm{M}$ sodium hydroxide was prepared by dissolving $20 \mathrm{~g}$ of sodium hydroxide in sufficient water. Thereafter, $40 \mathrm{~mL}$ of the prepared sodium hydroxide solution was transferred into the complex solution in a $250 \mathrm{~mL}$ beaker.

\section{Ammonia standard solutions}

A stock solution containing $100 \mathrm{ppm}(\mathrm{mg} / \mathrm{L})$ of ammonia was prepared by dissolving $0.3818 \mathrm{~g}$ of ammonium chloride in distilled water and diluting to $1000 \mathrm{~mL}$ with deionised water. Standard solutions in the concentration range of $0-5 \mathrm{ppm}(\mathrm{mg} / \mathrm{L})$ of ammonia were prepared by suitable dilutions of the prepared stock solution.

\section{Experimental}

\section{Fabrication of the $\mu P A D$}

The patterning of the microfluidic paper-based analytical device was designed using CorelDraw X7 software, followed by wax printing on chromatographic paper using a wax printer (Xerox Colorqube 8570). In general, identical patterns of wax were printed in alignment with the Whatman No.1 chromatography paper substrate which was cut to A4 size before use. The sheets of Whatman No.1 chromatography paper were directly fed into the printer. The print head dispenses ink (melted wax) on the surface of the paper, where it cools and solidifies instantly without further spreading. The ink is made of a mixture of hydrophobic compounds including carbamates, hydrocarbons and dyes that melt at around $120^{\circ} \mathrm{C}$. The $\mu \mathrm{PAD}$ were produced by the wax pattern manufacturing process.

The fabricated $\mu \mathrm{PAD}$ was then used for the colorimetric detection of ammonia using Nessler's reagent method (the mixture of $\mathrm{K}_{2} \mathrm{HgI}_{4}$ and $\mathrm{NaOH}$ or $\mathrm{KOH}$ ). The analysis of ammonia was achieved by dropping $10 \mu \mathrm{L}$ Nessler reagent and $5 \mu \mathrm{L}$ of potassium sodium tatrate into a reagent zone of the $\mu \mathrm{PAD}$ containing $20 \mu \mathrm{L}$ of ammonia standard solution of different concentrations ranging from 0 to $5 \mathrm{ppm}(\mathrm{mg} / \mathrm{L})$.

\section{Smartphone imaging}

Images of the $\mu \mathrm{PAD}$ were taken with a smartphone under fluorescent lighting conditions (laboratory lights). The smartphone camera light source was set on its continuous operation mode with flash off, a resolution of 3.9 M pixels (white balance, white fluorescent) and ISO camera speed of 100. The camera was focused on the $\mu$ PADs placed on a white bench surface; the images were then captured after $1 \mathrm{~min}$ of the observed colour change. The distance between the $\mu \mathrm{PAD}$ and the camera was fixed to $20 \mathrm{~cm}$ and the captured images were thereafter quantitatively analysed using ImageJ software.

\section{Analytical procedure}

The fabricated $\mu \mathrm{PAD}$ was evaluated for determination of ammonia in wastewater collected from Acacia effluent treatment plant (ETP) dam over 10 consecutive days. Acacia operation services is situated at Umbogintwini Industrial Complex (UIC) and is the owner of the complex and the only industry licensed to discharge 
(a)

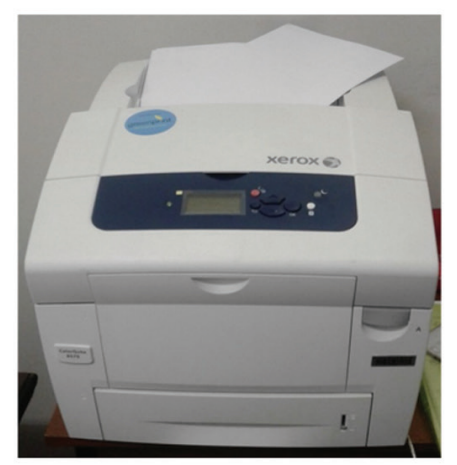

(b)

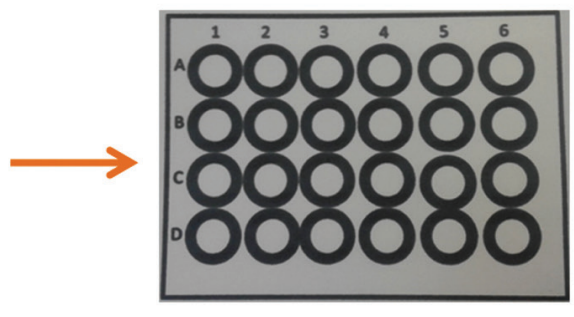

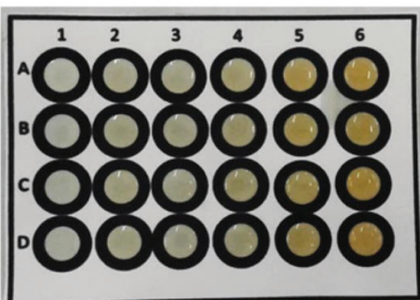

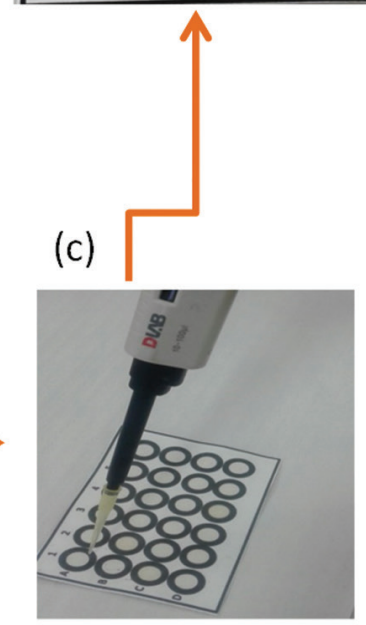

Figure 1. (a) Xerox wax printer for paper printing, (b) fabricated chromatographic paper, (c) heated chromatographic paper used for colorimetric detection of ammonia, (d) optimization of ammonia standards in reaction with the Nessler reagent resulting in colour development which is proportional to the concentration of standard, and (e) equation for reaction of Nessler reagent with ammonia producing a brown or intense yellow compound.

wastewater to the Kingsway Sea. Aqueous samples were collected as a composite sample. A mixture of samples was collected at 3 intervals: morning, evening and midnight. All samples for laboratory analysis were placed into thoroughly cleaned $1 \mathrm{~L}$ plastic bottles and tightly closed. Each bottle was rinsed with the appropriate amount of sample before final sample collection. These samples were placed in a cooler box, protected from direct sunlight, and taken to the laboratory for analysis. The $\mu \mathrm{PAD}$ results for samples that did not contain suspended particulate matter and coloured compounds were compared with those obtained by the standard spectrophotometric salicylate method.

The analytical procedure was conducted at room temperature and involved the deposition of $10 \mu \mathrm{L}$ of sample or standard solutions into the individual sample detection zones of the $\mu \mathrm{PAD}$, followed by the addition of $5 \mu \mathrm{L}$ of Nessler reagent. Addition of the Nessler reagent resulted in the colour change. The colour change was captured with a smartphone, and thereafter transferred to a computer for colour measurement. ImageJ software (National Institute of Health USA, http://imagej.nih.gov./ij) was used to measure the intensity of the colour formation in the detection zones. The RBG (red, green, blue) colour intensity profile plot was obtained for a chord passing through the centre of each detection zone. The highest sensitivity was obtained for green and red colours. This method was then validated by measuring the optical characteristics using a UV-visible spectrophotometer.

\section{RESULTS AND DISCUSSION}

\section{Optimization results}

The results obtained indicated that the intensity of the colour was directly proportional to the concentration of ammonia present in aqueous solution. The developed colours corresponding to various concentrations of ammonia are represented in Fig. 1. It can be observed that low ammonia concentrations resulted in the formation of a light-yellow colour on the $\mu \mathrm{PAD}$. The yellow colour became more intense at higher ammonia concentrations.

The experimental data obtained proved that the Nessler reagent was soluble in water and provided a clear colour change from colourless to yellow. The effect of the concentration of the Nessler reagent on the intensity value was studied in the range from $0-5 \mathrm{ppm}$. The intensity value increased rapidly with increasing concentration of ammonia.

A calibration curve (Fig. 2) for the colorimetric detection of ammonia with the Nessler reagent $\mu$ PAD was successfully obtained by a smartphone thus showing that colour intensity measurements of $\mu$ PADs could be conducted in the field. The analytical performance of the Nessler reagent was evaluated and

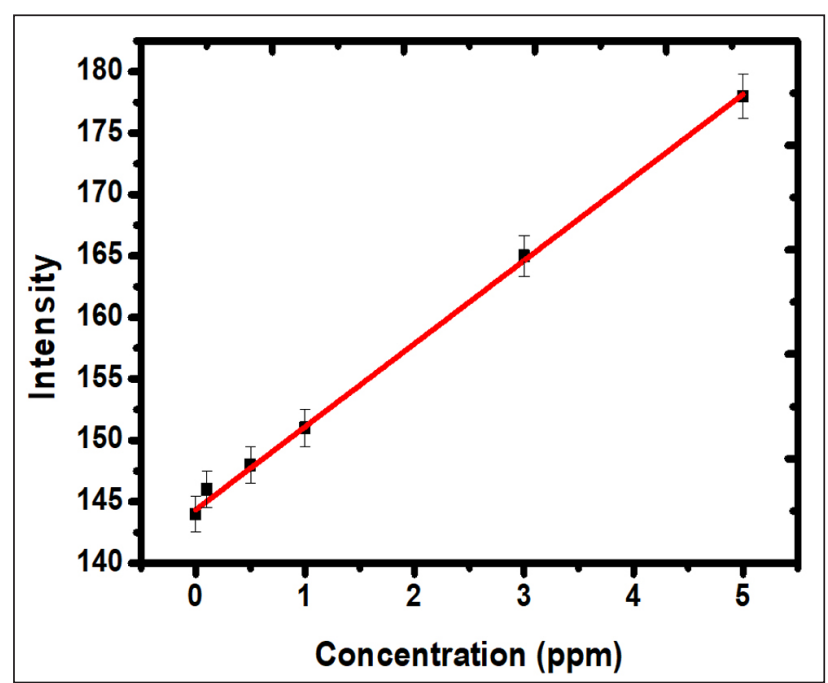

Figure 2. Linearity of intensity against concentration (ppm is equivalent to $\mathrm{mg} / \mathrm{L}$ ) 
the corresponding data are summarized in Table 1. Deionsed water was used as the blank. All colour intensity measurements were quadruplicated. The calibration curves of the Nessler reagent $\mu$ PADs for their corresponding linear ranges $(0-5 \mathrm{ppm})$ are described in Table 1 . The limit of detection $(n \geq 10)$ of the method was determined by the linear regression method of Miller and Miller.

Table 1. Analytical figures of merit (ppm is equivalent to $\mathrm{mg} / \mathrm{L}$ )

\begin{tabular}{lc}
\hline Parameters & Values \\
\hline Accuracy & $1.92 \pm 2.05$ \\
Slope & 5.8 \\
Intercept & 149.8 \\
Linearity & $0-5 \mathrm{ppm}$ \\
Correlation coefficient & 0.9644 \\
LOD & 3.37 \\
\hline
\end{tabular}

Table 2. Intensity results for the effluent treatment plant (ETP) samples (ppm is equivalent to $\mathrm{mg} / \mathrm{L}$ )

\begin{tabular}{lcc}
\hline ETP dam samples & Intensity & Nessler method \\
\cline { 3 - 3 } & & Concentration $(\mathrm{ppm})$ \\
\hline Day 1 & 170 & 4.51 \\
Day 2 & 165 & 3.85 \\
Day 3 & 150 & 1.49 \\
Day 4 & 158 & 2.70 \\
Day 5 & 156 & 2.39 \\
Day 6 & 155 & 2.24 \\
Day 7 & 154 & 2.09 \\
Day 8 & 143 & 0.43 \\
Day 9 & 148 & 1.19 \\
Day 10 & 158 & 0.10 \\
\hline
\end{tabular}

\section{Colour measurements}

In order to assess the possibility to use the device outside a laboratory setting, digital images of the paper devices were taken using a smartphone. The use of a smartphone would allow the user to be less reliant on expensive equipment and an established laboratory to complete the analysis (Moonrungsee et al., 2015). For example, to be able to use the paper device in the field the images of the paper devices could be sent via email to a central laboratory and analysed or the ImageJ software used to analyse the data from the paper device could be turned into a smartphonebased application (app) and analysed immediately using the mobile phone (Lopez-Ruiz et al., 2014; Shen et al., 2012). In this study the colour accuracy of the images captured for the $\mu$ PADs in the colorimetric detection of ammonia using Nessler reagent was determined by measuring the RGB (red, green and blue) values and using CIELab (Commission Internationale de l'Eclairage) colour space determination.

\section{RGB colour measurement}

The RGB colour model is based on the science of how the human eye peceives light and translates it into signals (Alala et al., 2014). The colorimetric image of ammonia detected was analysed for RGB values using ImageJ software. The obtained RGB colour histograms showing the pixels and the RGB values of each wastewater sample, performed in duplicate, are depicted in Fig 3. From a close look at the RGB pixels, it is seen that, for the more intense yellow-coloured samples the $R$ and $G$ values were shifting closer to the region of 225 , and the B value closer to 0 .

The RGB values and grayscale showed no monotonic change in response to the concentration value of $0-5 \mathrm{ppm}$ and narrow detectable concentration ranges with RGB values. This is due to the lack of colour information because the respective RGB values show only the information of redness, greenness or blueness of the resulting colours.

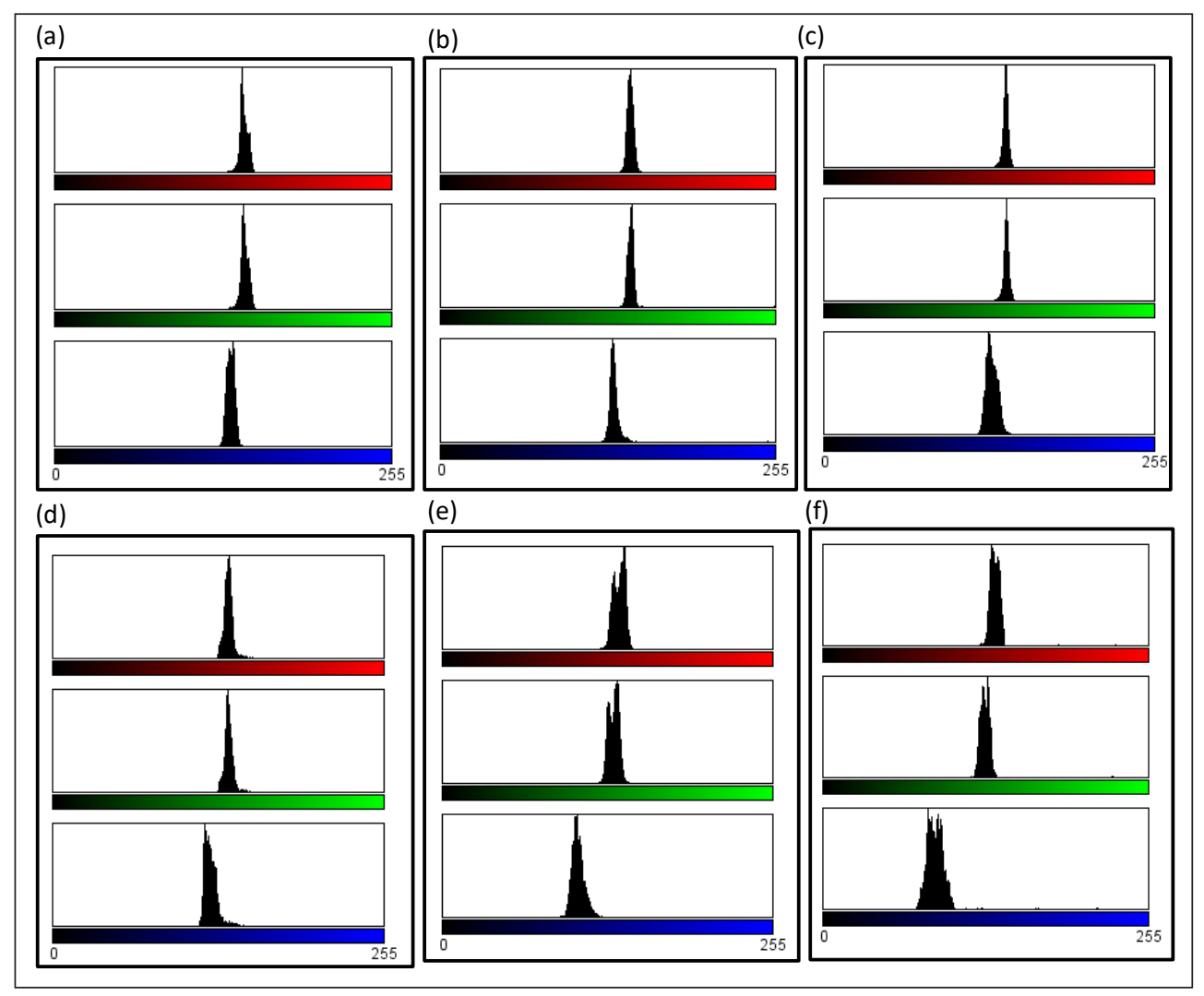

Figure 3. RGB colour distribution for ammonia standards where, (a) is for blank (b) 0.1 ppm, (c) 0.5 ppm, (d) 1 ppm, (e) 3 ppm and (f) 5 ppm (ppm is equivalent to $\mathrm{mg} / \mathrm{L}$ ) 


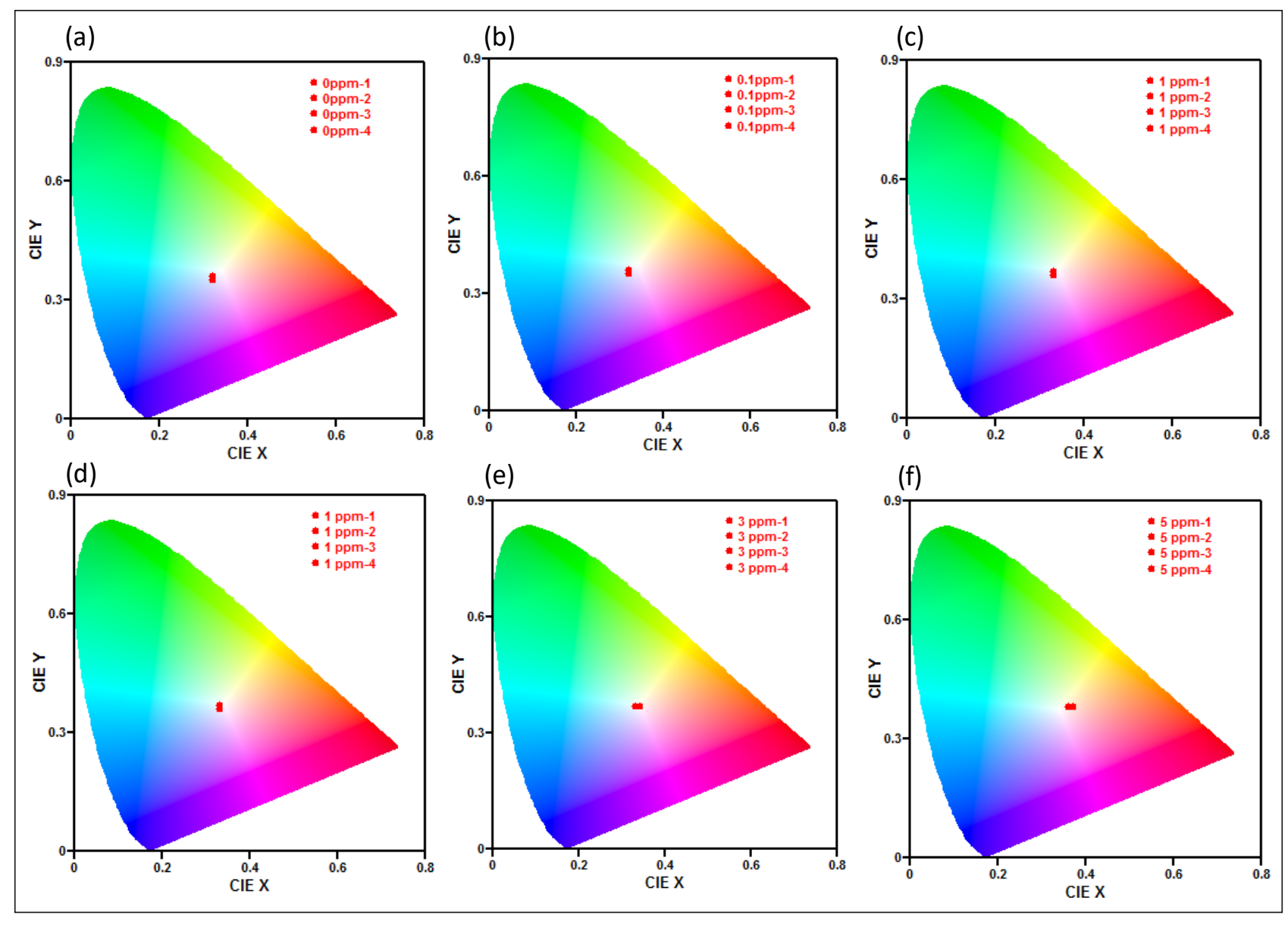

Figure 4. CIELAB Yxy chromaticity diagrams for (a) 0 ppm, (b) 0.1 ppm, (c) 0.5 ppm, (d) 1 ppm, (e) 3 ppm and (f) 5 ppm (ppm is equivalent to mg/L)

\section{CIELAB colour measurement}

From the RGB colour modeling, the RGB values were converted to $L^{*} a^{*} b^{*}$ using Hunter $L a b$ in order to obtained the CIE $L^{*} a^{*} b^{*}$ I Yxy colour space, a colour space $\left(L^{*} a^{*} b^{*}\right)$ in which $L$ represents lightness, $a^{*}$ represents the chromatic coordinates for red-green $\left(+a^{*}=\right.$ red direction, $-a^{*}=$ green direction $)$ and $b^{*}$ represents the chromaticity coordinate for yellow-blue $\left(+b^{*}=\right.$ yellow direction, $-b^{*}=$ blue direction). This colour space includes all perceivable colours it has a gamut that is greater than human vision. The chromatic diagrams for the CIEL Y $x y$ for the detected colour of each standard are shown in Fig. 4.

The chromaticity diagrams in Fig. 4 for quadruplicate analysis of each standard (from 0 to $5 \mathrm{ppm}$ ) showed that the colours were becoming more intensely yellow with the increase in concentration. The image analysis performed with the CIE $L^{*} a^{*} b^{*}$ colour coordinates $\left(L^{*}, a^{*}\right.$, and $\left.b^{*}\right)$ (Fig. 4$)$ indicated a trend in the data, accompanying an increase in concentration. It also shows dependencies of the concentration on each coordinate $\left(L^{*}, a^{*}\right.$, and $\left.b^{*}\right)$. There is a shift in the colour space coordinates of the $\mu \mathrm{PAD}$ images due to different ambient light conditions.

The CIELab colour difference between the predicted and measured shade tab colours were then used as indices of accuracy for the camera. Colour difference $(\Delta E)$ in Eq. 1 is defined by the following equation:

$$
\Delta \mathrm{E}=\sqrt{(\Delta \mathrm{L} *)^{2}+(\Delta \mathrm{a} *)^{2}+(\Delta \mathrm{b} *)^{2}} \Delta
$$

where $\Delta L^{*}, \Delta a^{*}$ and $\Delta b^{*}$ are the respective differences between the measured and predicted CIELAB values of the shade tabs. The colour difference for each standard was compared to that of a blank. The results for the calculated $\Delta E$ for each standard are shown in Fig. 4. If $\Delta E$ is between the values of 0.5 and 1.0, the difference is perceivable for experienced observers only and if $\Delta E$ ranges between 1 and 2 , it is said to be the minimal colour difference. A clear colour difference can be observed when $\Delta E$ is between 3 and 5 (Mokrzycki and Tatol, 2011). The calculated $\Delta E$ for each standard in Fig. 5 shows that the colour difference for $0.1 \mathrm{ppm}$ is normally undetectable, while for $0.5 \mathrm{ppm}$ there is a very small difference, only obvious to a trained eye; 1 ppm shows an obvious difference and 3-5 ppm shows a very obvious difference.

The $\Delta E$ plot for each standard in Fig. 5 showed that as concentration increased, the colours of the standards were significantly different at each concentration. Thus, it was observed that there was an increase in colour with the increase in concentration.

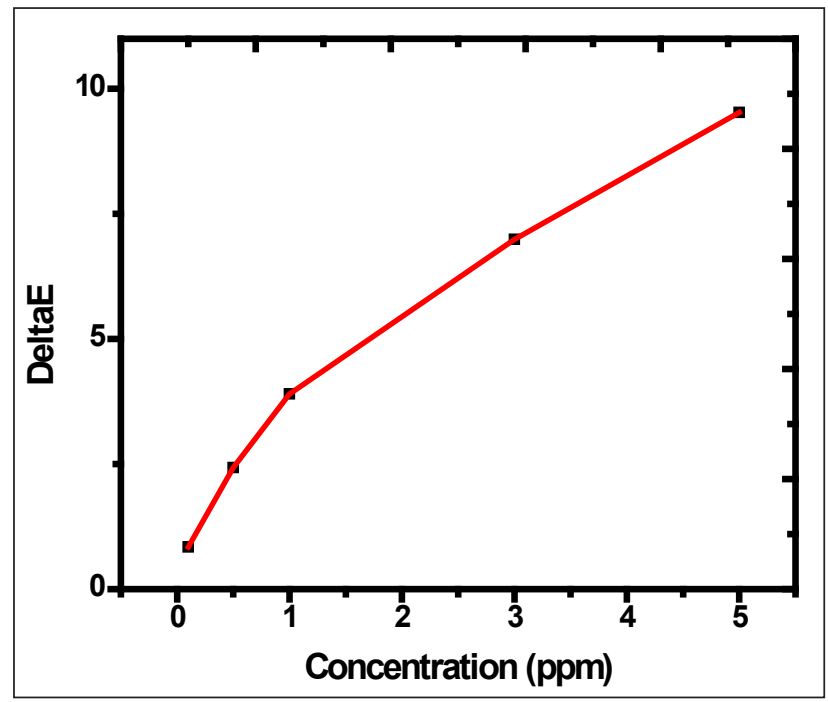

Figure 5. Calculated $\Delta E$ for each standard (ppm is equivalent to $\mathrm{mg} / \mathrm{L}$ ) 


\section{Analysis of wastewater samples}

The image from the colorimetric detection of ammonia in ETP dam samples is shown in Fig. 6. The results obtained in the evaluation of the Nessler reagent $\mu$ PADs for the determination of ammonia in wastewater samples are summarised in Table 2. The concentration of ammonia varies for each sample as shown in Fig. 6.

Traces of ammonia were detected in the ETP dam samples in ppm concentrations. The concentrations obtained from these samples were within the optimization range for the ammonia standards (0-5 ppm). This finding is consistent with Luo et al. (2015) who reported a detection range of $0.1-10 \mathrm{ppm}$ in wastewater samples.

Varying ammonia concentrations were detected from each sample. The Nessler method, with the change in colour intensity from pale yellow to intense yellow (Fig. 6) suggested the presence of ammonia. This finding was further supported by the previous work of Jeong and co-workers that showed that the presence of ammonia results in a change in colour from pale yellow to intense yellow (Jeong et al., 2013). The concentration of ammonia in samples taken over 10 days was found to be dissimilar. The traces of ammonia detected in UIC wastewater samples were in ppm concentration units (Table 2). For Days 1, 2, 4, 5, 6, and 7 there was a visible colour change observed. The change in colour observed from these samples indicated the presence of ammonia with each method. Martinez-Carballo and co-workers suggested that the detected ammonia concentrations may be due to the matrix effects being higher in the influents than in the effluents of WWTPs, which led to higher matrix suppression and higher

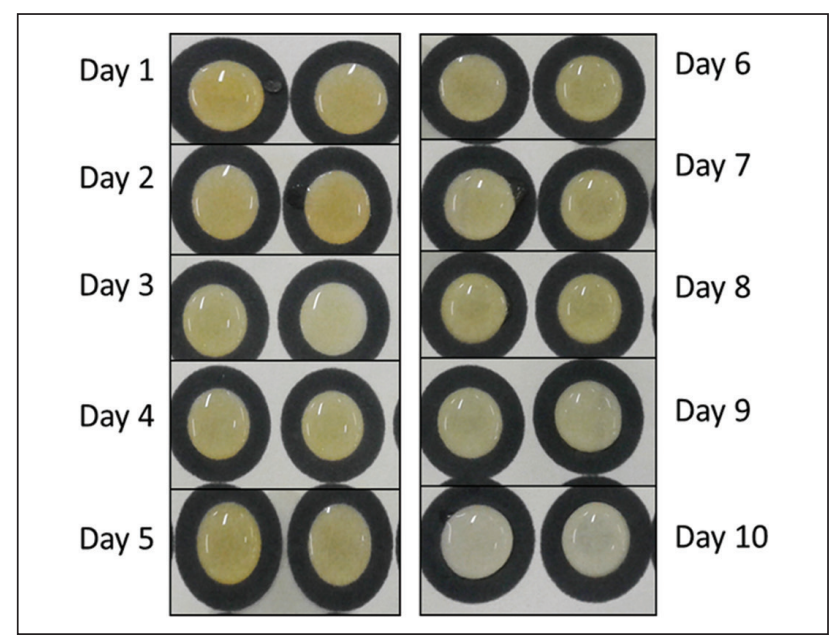

Figure 6. Colorimetric detection of the ETP samples

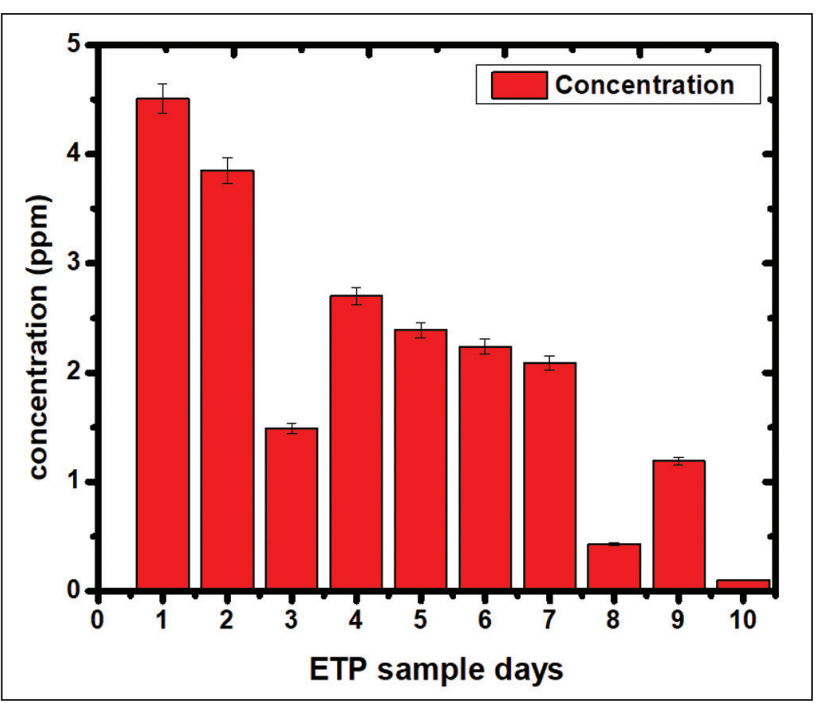

Figure 7. Ammonia concentration, ETP dam (ppm = mg/L) quantification limits in influents (Martínez-Carballo et al., 2007). In particular, naked eye observation of colour change for Days 3, 8,9 , and 10 , showed that there was a slight colour change, which was not visible enough. Therefore, the ammonia concentration detected from these samples was low. The colorimetric analysis of the Nessler reagent indicated that the resulting ammonia concentrations obtained from the UIC ETP dam wastewater samples was at the level of that of domestic wastewater, which indicates that it is permissible for it to be discharged directly to a sewer, as far as the nitrogen concentration is concerned.

Results presented in Fig. 7 show the colorimetric quantification of ammonia in a sample from the UIC ETP dam using the Nessler reagent method. It was observed that although the concentration of ammonia detected from Days 1-10 of the ETP samplingvaries, a gradual decrease was also noticed. An increase in ammonia level indicated a change in toxicity or $\mathrm{pH}$. The experimental data gathered confirmed that $\mu \mathrm{PAD}$ was highly successful in the quantification of ammonia.

\section{Interferences}

To evaluate the combined effect of inorganic ions present in wastewater $\left(\mathrm{Ca}^{2+}, \mathrm{Mg}^{2+}, \mathrm{Fe}^{2+}, \mathrm{Ni}^{2+}\right.$, and $\left.\mathrm{Cu}^{2+}\right)$ on the determination of ammonia, doubly concentrated 'very hard water', according to a standard recipe, was tested (Verdouw et al., 1978). The effect of potential interferences on the detection of ammonia in wastewater was studied by spiking each interference ion into the ammonia sample. The observed colour change image is depicted in Fig. 8.

It was observed that for $\mathrm{Ca}^{2+}$ there was no intense yellow colour; instead, a dark brown colour with gelatinous black precipitate was observed. For $\mathrm{Ni}^{2+}, \mathrm{Cu}^{2+}, \mathrm{Ca}^{2+}$ and $\mathrm{Mg}^{2+}$ an intense yellow colour was observed. The quantitative recoveries of ammonia presented in Table 3 were in the range of $96-106 \%$.

Table 3. Ammonia interference from inorganic ions (ppm is equivalent to $\mathrm{mg} / \mathrm{L}$ )

\begin{tabular}{lcc}
\hline Interferences & Concentration $(\mathrm{ppm})$ & \% recovery \\
\hline $\mathrm{Fe}^{2+}$ & 3.51 & 104 \\
$\mathrm{Cu}^{2+}$ & 4.62 & 101 \\
$\mathrm{Mn}^{2+}$ & 4.28 & 106 \\
$\mathrm{Ni}^{2+}$ & 5.22 & 96 \\
$\mathrm{Ca}^{2+}$ & 4.11 & 96 \\
\hline
\end{tabular}

$n=2$

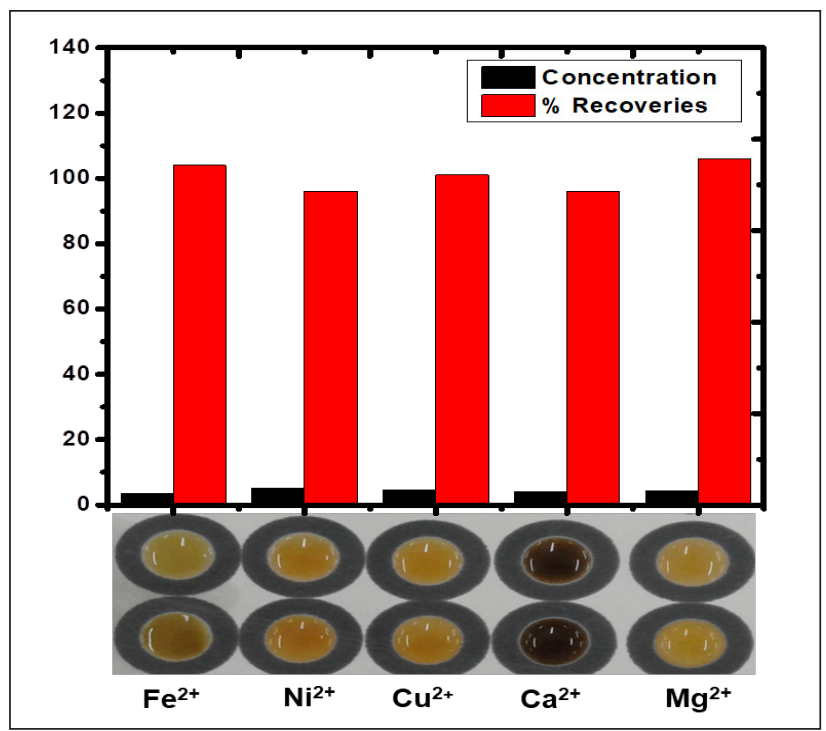

Figure 8. Colorimetric detection of ammonia interfering ions in wastewater. Concentration in ppm (mg/L) 
Table 4. Comparison of different approaches used for the detection of ammonia (ppm is equivalent to $\mathrm{mg} / \mathrm{L}$ )

\begin{tabular}{|c|c|c|c|}
\hline Method & LOD & Linear range & Reference \\
\hline $\begin{array}{l}\text { Colorimetric detection of ammonia using smartphones based on localized } \\
\text { surface plasmon resonance of silver nanoparticles }\end{array}$ & 190 ppm & $10-1000$ ppm & Amirjani and Fatmehsari, 2018 \\
\hline $\begin{array}{l}\text { Determination of ammonia nitrogen in solid and liquid high-complex matrices } \\
\text { using one-step gas-diffusion micro-extraction and fluorimetric detection }\end{array}$ & $0.22 \mathrm{ppm}$ & $0.38-6.27 \mathrm{ppm}$ & Valente et al., 2017 \\
\hline $\begin{array}{l}\text { Determination of trace levels of ammonia in marine water using a simple } \\
\text { environmentally friendly ammonia (SEA) analyser }\end{array}$ & $15.88 \mathrm{nM}$ & $0.28-13.9 \mu \mathrm{M}$ & O'Connor Šraj et al., 2017 \\
\hline A simple method for determining ammonia in water at the ppm level & NM & $0-10$ ppm & Boo and Ma, 1976 \\
\hline A ratiometric fluorescence sensor for the detection of ammonia in water & NM & $1-60 \mathrm{ppm}$ & Duong and Rhee, 2014 \\
\hline $\begin{array}{l}\text { Development of a microfluidic paper-based analytical device for the } \\
\text { quantification of ammonia }\end{array}$ & 3.37 & $0-5$ ppm & This work \\
\hline
\end{tabular}

NM - not mentioned

These recoveries indicated that the proposed $\mu \mathrm{PAD}$ can be used for the determination of ammonia in wastewater samples. Accurate analysis of ammonia content using the Nessler method cannot be possible when $\mathrm{Ca}^{2+}$ is present in wastewater samples. $\mathrm{Ca}^{2+}$ in wastewater is known to precipitate and forms a complex with salts in the Nessler reagent. The modified Nessler method could not accurately quantify ammonia in water samples with $\mathrm{Ca}^{2+}$. Therefore, a stabilizer solution of potassium sodium tartrate should be added to halt the development of cloudiness of the Nessler reagent which may occur in some wastewaters because of calcium interference.

\section{Applicability of the colorimetric method}

The accuracy of the proposed method in this paper was comparable with that of previously published techniques. It is worthwhile to note that the linear ranges presented in Table 4 are wider than those measured for the proposed method. Also, this method holds the advantages of simplicity and rapidity as well as the fact that microfluidic paper-based detection of ammonia is a low-cost analytical method which can detect even the smallest concentration of the analyte.

\section{CONCLUSIONS}

Although $\mu$ PADs were originally developed as biomedical assays for point-of-care diagnostics (Chong et al., 2013), their use has expanded into environmental research. Relative to the progress achieved in biomedical devices, environmental monitoring with $\mu$ PADs is still in its infancy. The microfluidic paper-based analytical device for the direct determination of ammonia in wastewater has been successfully developed. This paper has reported the optimisation parameters of a simplified Nessler reagent to facilitate the integration of the device into an analysis system, resulting in a simple procedure for the real-time measurement of ammonia in wastewater, with a lower limit of detection achieved of $3.37 \mathrm{ppm}$.

The feasibility of detecting coloured solutions based on the image colour analysis method was studied. The results showed that the $\mu \mathrm{PAD}$ permitted the method's simple design and easy operation, and provided a simple method to detect the concentration of ammonia in wastewater through the application of computer image processing technology and colour analysis technology. The RGB and the CIELAB colour space were used for computational colour analysis, and the colour difference $(\Delta E)$ calculation proved that for each standard the colour is different.

Compared with traditional methods, the proposed method has the advantages of high automation, low cost, simple instrument design, and a user-friendly interface. This is suitable for fast water quality detection in the field, and has wide application prospects for measurement and computer science.

\section{REFERENCES}

ALALA B, MWANGI W and OKEYO G (2014) Image representation using RGB color space. Int. J. Innov. Res. Dev. 3 (8) pp.

AMIRJANI A and FATMEHSARI DH (2018) Colorimetric detection of ammonia using smartphones based on localized surface plasmon resonance of silver nanoparticles. Talanta 176 242-246. https://doi. org/10.1016/j.talanta.2017.08.022

BALDEVBHAI PJ and ANAND R (2012) Color image segmentation for medical images using $\mathrm{L}^{*} \mathrm{a}^{*} \mathrm{~b}^{*}$ color space. IOSR J. Electron. Commun. Eng. 1 (2) 24-45. https://doi.org/10.9790/2834-0122445

BOO H-K and MA T (1976) A simple method for determining ammonia in water at the ppm level. Microchim. Acta 66 (5-6) 515-523. https:// doi.org/10.1007/BF01220109

CHONG H, KOO Y, COLLINS B, GOMEZ F, YUN Y and SANKAR J (2013) Paper-based microfluidic point-of-care diagnostic devices for monitoring drug metabolism. J. Nanomed. Biotherm. Discovery 3 e122. https://doi.org/10.4172/2155-983X.1000e122

COLT J and HUGUENIN JE (2002) Design and Operating Guide for Aquaculture Seawater Systems. Elsevier, London.

CONSORTIUM IC (2004) Image technology colour management architecture, profile format, and data structure. Specification ICC. 1: 2004-10 (Profile version 4.2. 0.0).

DUONG HD and RHEE JI (2014) A ratiometric fluorescence sensor for the detection of ammonia in water. Sens. Actuators B: Chem. 190 768-774. https://doi.org/10.1016/j.snb.2013.09.071

FAIRCHILD MD (1993) The CIE 1931 standard colorimetric observer: Mandatory retirement at age 65? Color Res. Appl. 18 (2) 129-134. https://doi.org/10.1002/col.5080180210

GONG MM and SINTON D (2017) Turning the page: advancing paperbased microfluidics for broad diagnostic application. Chem. Rev. 117 (12) 8447-8480. https://doi.org/10.1021/acs.chemrev.7b00024

GUO Z, ZHENG Z, GU C and ZHENG Y (2008) Gamma irradiationinduced removal of low-concentration nitrite in aqueous solution. Radiat. Phys. Chem. 77 (6) 702-707. https://doi.org/10.1016/j.radphys chem.2007.10.002

ISLAM M and PATEL R (2010) Synthesis and physicochemical characterization of $\mathrm{Zn} / \mathrm{Al}$ chloride layered double hydroxide and evaluation of its nitrate removal efficiency. Desalination 256 (1) 120-128. https://doi.org/10.1016/j.desal.2010.02.003

JAYAWARDANE BM, MCKELVIE ID and KOLEV SD (2015) Development of a gas-diffusion microfluidic paper-based analytical device $(\mu \mathrm{PAD})$ for the determination of ammonia in wastewater samples. Anal. Chem. 87 (9) 4621-4626. https://doi.org/10.1021/acs. analchem.5b00125

JEONG H, PARK J and KIM H (2013) Determination of $\mathrm{NH}_{4}{ }^{+}$in environmental water with interfering substances using the modified Nessler method. J. Chem. 2013 9. https://doi.org/10.1155/2013/359217

JORGENSEN TC (2002) Removal of ammonia from wastewater by ion exchange in the presence of organic compounds. Thesis, University of Canterbury, New-Zealand. 
KOCH FC and MCMEEKIN TL (1924) A new direct nesslerization micro-kjeldahl method and a modification of the Nessler-Folin reagent for ammonia. J. Am. Chem. Soc. 46 (9) 2066-2069. https:// doi.org/10.1021/ja01674a013

LEE CG, FLETCHER TD and SUN G (2009) Nitrogen removal in constructed wetland systems. Eng. Life Sci. 9 (1) 11-22. https://doi. org/10.1002/elsc.200800049

LEÓN K, MERY D, PEDRESCHI F and LEÓN J (2006) Color measurement in $\mathrm{L} * \mathrm{a} * \mathrm{~b} *$ units from RGB digital images. Food Res. Int. 39 (10) 1084-1091. https://doi.org/10.1016/j.foodres.2006.03.006

LOPEZ-RUIZ N, CURTO VF, ERENAS MM, BENITO-LOPEZ F, DIAMOND D, PALMA AJ and CAPITAN-VALLVEY LF (2014) Smartphone-based simultaneous $\mathrm{pH}$ and nitrite colorimetric determination for paper microfluidic devices. Anal. Chem. 86 (19) 9554-9562. https://doi.org/10.1021/ac5019205

LUO X, YAN Q, WANG C, LUO C, ZHOU N and JIAN C (2015) Treatment of ammonia nitrogen wastewater in low concentration by two-stage ozonization. Int. J. Environ. Res. Public Health 12 (9) 11975-11987. https://doi.org/10.3390/ijerph120911975

MARKOU G, VANDAMME D and MUYLAERT K (2014) Using natural zeolite for ammonia sorption from wastewater and as nitrogen releaser for the cultivation of Arthrospira platensis. Bioresour. Technol. 155 373-378. https://doi.org/10.1016/j.biortech.2013.12.122

MARTÍNEZ-CARBALLO E，SITKA A, GONZÁLEZ-BARREIRO C, KREUZINGER N, FÜRHACKER M, SCHARF S and GANS O (2007) Determination of selected quaternary ammonium compounds by liquid chromatography with mass spectrometry. Part I. Application to surface, waste and indirect discharge water samples in Austria. Environ. Pollut. 145 (2) 489-496. https://doi. org/10.1016/j.envpol.2006.04.033

MARTINEZ AW, PHILLIPS ST, WHITESIDES GM and CARRILHO E (2010) Diagnostics for the developing world: microfluidic paperbased analytical devices. Anal. Chem. 82 (1) 3-10. https://doi.org/ 10.1021/ac9013989

MEREDITH NA, QUINN C, CATE DM, REILLY TH, VOLCKENS $J$ and HENRY CS (2016) Paper-based analytical devices for environmental analysis. Analyst 141 (6) 1874-1887. https://doi. org/10.1039/C5AN02572A

MOKRZYCKI W and TATOL M (2011) Colour difference $\Delta$ E-A survey. Mach. Graphics Vision 20 (4) 383-411.

MOONRUNGSEE N, PENCHAREE S and JAKMUNEE J (2015) Colorimetric analyzer based on mobile phone camera for determination of available phosphorus in soil. Talanta 136 204-209. https://doi.org/10.1016/j.talanta.2015.01.024
NIE J, ZHANG Y, LIN L, ZHOU C, LI S, ZHANG L and LI J (2012) Lowcost fabrication of paper-based microfluidic devices by one-step plotting. Anal. Chem. 84 (15) 6331-6335. https://doi.org/10.1021/ ac203496c

O'CONNOR ŠRAJ L, ALMEIDA MIGS, MCKELVIE ID and KOLEV SD (2017) Determination of trace levels of ammonia in marine waters using a simple environmentally-friendly ammonia (SEA) analyser. Mar. Chem. 194 133-145. https://doi.org/10.1016/j.marchem.2017.06. 008

SHEN L, HAGEN JA and PAPAUTSKY I (2012) Point-of-care colorimetric detection with a smartphone. Lab on a Chip 12 (21) 4240-4243. https://doi.org/10.1039/c2lc40741h

SRIVASTAVA R, VERMA A and JAIN VK (2012) Low cost, disposable colorimetric sensor for quantitative detection of ammonia gas. Proc. SPIE 8549, $16^{\text {th }}$ International Workshop on Physics of Semiconductor Devices, 85491A (15 October 2012). https://doi.org/10.1117/12.925176 THOMPSON J and MORRISON G (1951) Determination of organic nitrogen. Control of variables in the use of Nessler's Reagent. Anal. Chem. 23 (8) 1153-1157. https://doi.org/10.1021/ac60056a029

VALENTE IM, OLIVEIRA HM, VAZ CD, RAMOS RM, FONSECA AJM, CABRITA ARJ and RODRIGUES JA (2017) Determination of ammonia nitrogen in solid and liquid high-complex matrices using one-step gas-diffusion microextraction and fluorimetric detection. Talanta 167 747-753. https://doi.org/10.1016/j.talanta.2017.01.091

VERDOUW H, VAN ECHTELD CJA and DEKKERS EMJ (1978) Ammonia determination based on indophenol formation with sodium salicylate. Water Res. 12 (6) 399-402. https://doi.org/10.1016/ 0043-1354(78)90107-0

WIESMANN U (1994) Biological nitrogen removal from wastewater. In: Thomas S (ed.) Biotechnics/Wastewater. Springer, Berlin. 113154. https://doi.org/10.1007/BFb0008736

WYSZECKI G (1968) Technical notes: Recent agreements reached by the colorimetry committee of the commission internationale de l'eclairage. J Opt. Soc. Am. 58 (2) 290-292. https://doi.org/10.1364/ JOSA.58.000290

YAMADA K, HENARES TG, SUZUKI K and CITTERIO D (2015) Paper-based inkjet-printed microfluidic analytical devices. Angew Chem. Int. Ed. Engl. 54 (18) 5294-5310. https://doi.org/10.1002/ anie. 201411508

YANG $\mathrm{H}$ and CHENG H (2007) Controlling nitrite level in drinking water by chlorination and chloramination. Sep. Purif. Technol. 56 (3) 392-396. https://doi.org/10.1016/j.seppur.2007.05.036 